\title{
On the Inconsistent Relationship between Pacific and Atlantic Niños*
}

\author{
JoKe F. LÜBBECKe AND Michael J. MCPHADEN \\ NOAA/Pacific Marine Environmental Laboratory, Seattle, Washington
}

(Manuscript received 29 September 2011, in final form 20 December 2011)

\begin{abstract}
The tropical Atlantic wind response to El Niño forcing is robust, with weakened northeast trade winds north of the equator and strengthened southeast trade winds along and south of the equator. However, the relationship between sea surface temperature (SST) anomalies in the eastern equatorial Pacific and Atlantic is inconsistent, with El Niño events followed sometimes by warm and other times by cold boreal summer anomalies in the Atlantic cold tongue region. Using observational data and a hindcast simulation of the Nucleus for European Modeling of the Ocean (NEMO) global model at $0.5^{\circ}$ resolution (NEMO-ORCA05), this inconsistent SST relationship is shown to be at least partly attributable to a delayed negative feedback in the tropical Atlantic that is active in years with a warm or neutral response in the eastern equatorial Atlantic. In these years, the boreal spring warming in the northern tropical Atlantic that is a typical response to El Niño is pronounced, setting up a strong meridional SST gradient. This leads to a negative wind stress curl anomaly to the north of the equator that generates downwelling Rossby waves. When these waves reach the western boundary, they are reflected into downwelling equatorial Kelvin waves that reach the cold tongue region in late boreal summer to counteract the initial cooling that is due to the boreal winter wind stress response to El Niño. In contrast, this initial cooling persists or is amplified in years in which the boreal spring northern tropical Atlantic warming is weak or absent either because of a positive North Atlantic Oscillation (NAO) phase or an early termination of the Pacific El Niño event.
\end{abstract}

\section{Introduction}

The Pacific El Niño-Southern Oscillation (ENSO) is the globally dominant mode of variability on interannual time scales (McPhaden et al. 2006). It has an impact on tropical Atlantic variability mainly via two mechanisms. First, during El Niño, atmospheric wave trains propagate through the extratropics of the Northern Hemisphere, weakening the northeast trade winds in the Atlantic. Second, anomalous convection in the eastern tropical Pacific during the mature phase of El Niño alters the Walker circulation, leading to strengthened easterly winds in the western equatorial Atlantic (Sutton et al. 2000; Huang 2004). Thus, a typical Atlantic wind response to El Niño involves a weakening of the northeasterly trades and a strengthening of the southeasterly trades in the western equatorial Atlantic early in the

\footnotetext{
* Pacific Marine Environmental Laboratory Publication Number 3751.

Corresponding author address: Joke Lübbecke, PMEL/OCRD_BLDG 3, 7600 Sand Point Way NE, Seattle, WA 98115.

E-mail: joke.luebbecke@noaa.gov
}

calendar year following an El Niño peak (Fig. 1a). While the former is associated with a warming of the northern tropical Atlantic (NTA), the latter generates upwelling equatorial Kelvin waves that can lead to cooling in the eastern equatorial Atlantic (EEA). The interaction between western and central equatorial Atlantic wind stress, eastern equatorial thermocline depth, and EEA SST is the underlying mechanism of the so-called Atlantic zonal mode or Atlantic Niño, a tropical Atlantic climate mode that is dominated by ocean dynamics and oceanatmosphere interactions similar to the Bjerknes feedback in the tropical Pacific (e.g., Carton et al. 1996; RuizBarradas et al. 2000). The season in which the equatorial Atlantic response to El Niño is expected to be most strongly developed is boreal summer, when zonal mode variability peaks because of the shallow eastern Atlantic thermocline and a maximum in upwelling (Keenlyside and Latif 2007).

A robust response to El Niño in SST is, however, only found in the NTA with a warming in the boreal spring following a boreal winter El Niño peak (Enfield and Mayer 1997; Huang et al. 2002). In contrast, SST in the Atlantic cold tongue region can be either warm or cold in the boreal summer following an El Niño event. 

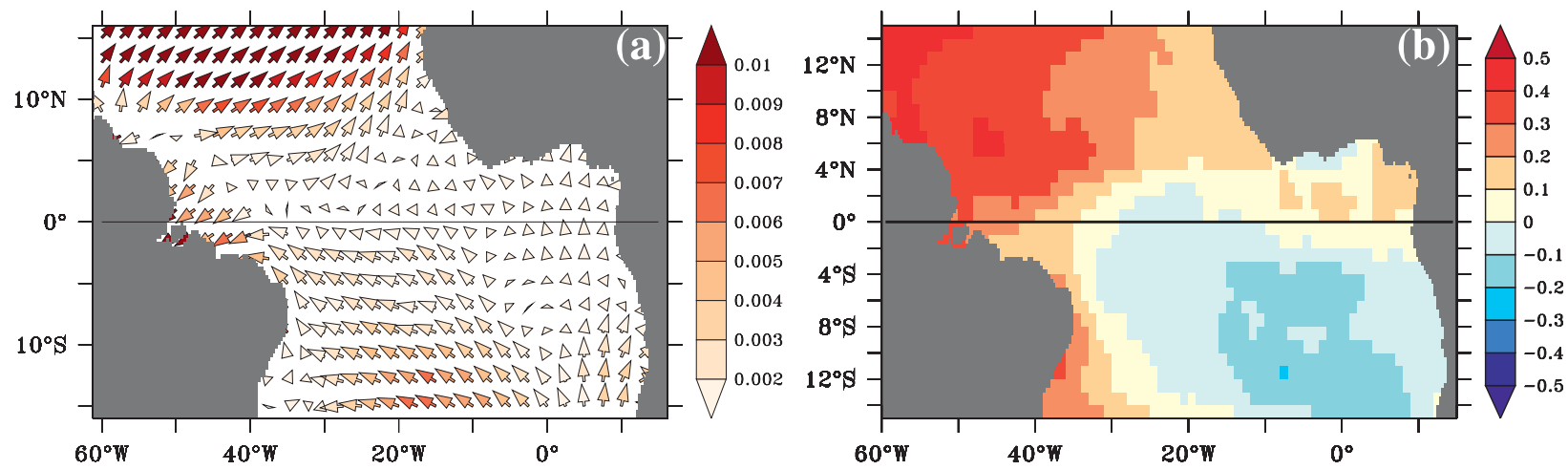

FIG. 1. Typical tropical Atlantic response to El Niño. (a) Composite difference in January-March (JFM) NCEP-NCAR wind stress between El Niño (+1) years (according to the classification by the NOAA National Weather Service: http://www.cpc.ncep.noaa.gov/ products/analysis_monitoring/ensostuff/ensoyears.shtml) and the climatological mean (1948-2010). (b) Correlation between observed Niño-3 time series and tropical Atlantic interannual SST anomalies for 1982-2009 with Niño-3 leading by 6 months.

Different studies based on both models and observations have come to very different conclusions about the influence of El Niño on Atlantic equatorial SST. For example, positive SST anomalies in the eastern equatorial Atlantic were found to lag those in the equatorial Pacific by 6 months in a cross-spectral analysis of observational SST data by Latif and Grötzner (2000). Lohmann and Latif (2007) found a boreal summer warming in the entire tropical Atlantic apart from weak cooling in the eastern equatorial basin in their composite analysis of observed SST data. On the contrary, a coupled general circulation model (CGCM) analysis by Huang (2004) argued for cold SST anomalies in the tropical Atlantic in the boreal summer following an El Niño because of the dynamical response to anomalous easterlies. Accordingly, lagged correlations between SST anomalies in the eastern equatorial Pacific, represented by the Niño-3 $\left(5^{\circ} \mathrm{S}-5^{\circ} \mathrm{N}, 150^{\circ}-90^{\circ} \mathrm{W}\right)$ region, and in the eastern equatorial Atlantic, represented by the Atlantic-3 (ATL3) $\left(3^{\circ} \mathrm{S}-3^{\circ} \mathrm{N}, 20^{\circ} \mathrm{W}-0^{\circ} \mathrm{E}\right)$ region, are not significant for the Pacific leading the Atlantic (Keenlyside and Latif 2007, their Fig. 6b). In particular, the correlation between interannual National Oceanic and Atmospheric Administration (NOAA) optimum interpolation (OI) SST anomalies in the tropical Atlantic and averaged over the Niño-3 region with the Niño-3 index leading by 6 months does not exceed 0.2 in the EEA (Fig. 1b). Thus, the dynamical connection between interannual SST variability in the tropical Pacific and Atlantic is still a controversial issue. The inconsistent relationship between Pacific and Atlantic cold tongue SST anomalies has been interpreted by Chang et al. (2006) in terms of a destructive interference between the tropospheric temperature-induced warming (Chiang and Sobel 2002; Chiang and Lintner 2005) that favors a basinwide temperature increase and the Bjerknes-type ocean dynamical response that would produce cooling in the EEA (Latif and Barnett 1995).

In this study we propose a different mechanism that can at least partly explain the inconsistent Atlantic cold tongue response to Pacific El Niño events, namely, a delayed negative feedback process. This mechanism was first described by Foltz and McPhaden (2010) to explain the impact of the Atlantic meridional mode on the zonal mode. They suggest that there are two competing influences. The first is due to Kelvin waves that are excited because of a zonal wind stress anomaly on the equator that is associated with an anomalous meridional SST gradient in boreal spring. The second is due to Rossby waves that are reflected into Kelvin waves of opposite sign and thus act as a delayed negative feedback on the eastern equatorial SST anomalies. Here we examine the role of this mechanism in the response of the tropical Atlantic to El Niño. We hypothesize that in addition to a direct cooling response initiated by the strengthening of the southeasterly trades, the wind stress change introduced by the meridional SST gradient that develops in response to El Niño can excite downwelling Rossby waves north of the equator. These Rossby waves reflect into downwelling Kelvin waves that counteract the initial cooling and potentially even lead to a boreal summer warming in the EEA. Depending on the strength of the meridional SST gradient and the associated change in wind stress and wind stress curl, the delayed negative feedback via Rossby waves may be more or less dominant. A similar idea involving the opposing effect of downwelling Rossby waves and anomalous equatorial easterlies was suggested by Xie and Carton (2004). They did not, however, demonstrate that the concept was operative, which is the purpose of the present study.

The remainder of the paper is organized as follows. In section 2, the observational data and the model used in this study are briefly described. Section 3 presents 
observational evidence for the delayed negative feedback and then a statistical analysis based on output from an ocean general circulation model. Section 4 provides a summary of the results and conclusions.

\section{Model and observational data}

All datasets that are used in this study have been detrended prior to further analysis. To calculate interannual anomalies, a repeated seasonal cycle was subtracted from the original data. To focus entirely on the interannual signal, the decadal variability has been removed as well from the monthly model output data that are shown in section $3 \mathrm{~b}$. This is done by subtracting a decadally filtered time series - that is, a monthly time series to which a 119-point ( $\sim 10 \mathrm{yr})$ Hanning filter has been applied-from the original data.

\section{a. Observational datasets}

We use monthly NOAA optimum interpolation SST data with a spatial resolution of $1^{\circ}$, provided by NOAA/ Earth System Research Laboratory/Physical Sciences Division, Boulder, Colorado. These data consist of a blend of satellite and in situ observations (Reynolds et al. 2002) and span the period from November 1981 to present. For observations of sea surface height (SSH), we use the weekly satellite data produced and distributed by Archiving, Validation, and Interpretation of Satellite Oceanographic data (AVISO; www.aviso.oceanobs.com). This product has a horizontal resolution of $0.25^{\circ}$ and spans the period from January 1993 to the present. For wind stress, the National Centers for Environmental Prediction (NCEP)-National Center for Atmospheric Research (NCAR) reanalysis data are used (Kalnay et al. 1996). They are available from 1948 to the present with a T62 horizontal resolution.

\section{b. Model configuration}

Because there are only a few El Niño events during the time period for which SSH observations are available, output from a numerical circulation model simulation that covers more events are additionally used. Monthly and 5-day-average fields for temperature and SSH are used from the global ocean-sea ice model Nucleus for European Modeling of the Ocean (NEMO; Madec 2008) at $0.5^{\circ}$ horizontal resolution (NEMOORCA05), implemented by the European Drakkar collaboration (Drakkar Group 2007). In the vertical, there are 46 geopotential levels of variable thickness with the highest resolution in the top $500 \mathrm{~m}$. Lateral mixing is oriented along isopycnals and vertical mixing is achieved using the turbulent kinetic energy (TKE) scheme of Blanke and Delecluse (1993). The experiment used in this study is described in more detail as the control experiment in Lorbacher et al. (2010). It is a hindcast simulation forced by an interannually varying atmosphere spanning the period 1958-2004. Monthly output is available for the whole time period and 5-day-average output for 1970-2004. The surface boundary conditions for momentum, heat, and freshwater are implemented according to the protocol suggested for Coordinated Ocean-Ice Reference Experiments (COREs; Griffies et al. 2009), utilizing the bulk forcing methodology developed by Large and Yeager (2004) and Large (2007). The atmospheric forcing is based on NCEP-NCAR reanalysis products, merged with various observational (e.g., satellite) products for radiation (interannual varying from 1984 on), precipitation (interannual varying from 1979 on), and runoff (climatological) fields. The model integration was initialized with the annual mean temperature and salinity distributions of the Levitus climatology (Levitus et al. 1998) for low and midlatitudes, and from the dataset of the Polar Hydrographic Center (PHC 2.1) for high latitudes (Steele et al. 2001). The phase speeds of equatorial Kelvin waves calculated from the model's Brunt-Väisälä frequency profile in the equatorial Atlantic are $2.86 \mathrm{~m} \mathrm{~s}^{-1}$ for the first, $1.67 \mathrm{~m} \mathrm{~s}^{-1}$ for the second, and $1.25 \mathrm{~m} \mathrm{~s}^{-1}$ for the third baroclinic mode.

\section{c. Model validation}

Before discussing the tropical Atlantic response to El Niño events, it is useful to compare some key quantities of the model solution to observations. Time series of interannual SST anomalies averaged over the eastern equatorial Pacific and Atlantic region (Fig. 2) show good agreement between the model data and observations, with correlation values of 0.90 for the Niño-3 and 0.84 for the ATL3 indices. Using a standard Student's $t$ test with degrees of freedom determined from the autocorrelation functions of the time series, both values are found to be significant at the $95 \%$ level. Note that SST is not a fully prognostic variable in the model because of the implicit damping of SST toward prescribed surface air temperature values resulting from the bulk formulation for the turbulent heat flux. A previous version of the same model, however, was also able to realistically simulate eastern tropical Atlantic Niños and their generation (Lübbecke et al. 2010), with the impact of winddriven circulation changes on near-surface temperature variability reflected by temperature variations below the mixed layer (Lübbecke et al. 2008).

Figure 3 shows time series of interannual SSH anomalies from the model and observations averaged zonally over the Atlantic basin from $40^{\circ} \mathrm{W}$ to $10^{\circ} \mathrm{E}$ and meridionally over the two bands that will be used to detect Kelvin and Rossby wave propagation, namely, $2^{\circ} \mathrm{S}-2^{\circ} \mathrm{N}$ and $2^{\circ}-5^{\circ} \mathrm{N}$. 


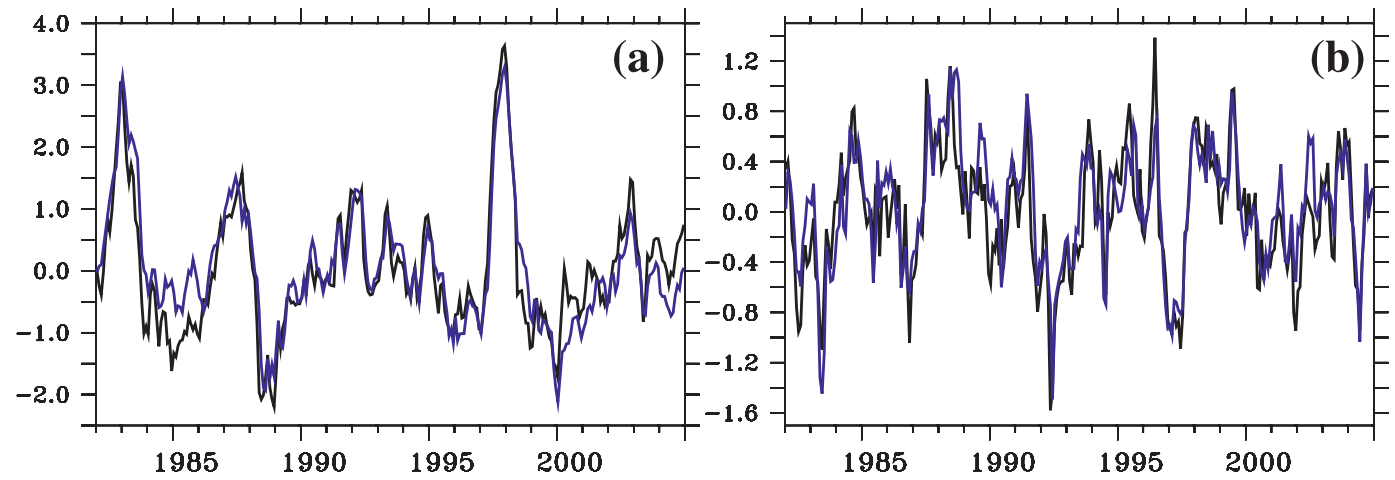

FIG. 2. Interannual SST anomalies $\left({ }^{\circ} \mathrm{C}\right)$ averaged over (a) Niño-3 and (b) ATL3 region from observations (black) and NEMO-ORCA05 model (blue).

The variability is similar with correlations of 0.73 for the equatorial band and 0.65 for the northern band. Additionally, shown in Fig. 3 are corresponding anomalies in the simulated depth of the $23^{\circ} \mathrm{C}$ isotherm (z23), which is a measure of the thermocline depth (Florenchie et al. 2003). The thermocline depth and SSH anomalies from the model simulation agree well with correlations of 0.84 and 0.63 , respectively, as a consequence of the fact that the tropical Atlantic behaves much like a two-layer system. All the correlations shown for SSH and z23 are significant at the $95 \%$ level. We conclude that the model simulation captures the tropical ocean variability important for this study and can thus be used to systematically analyze the tropical Atlantic response to Pacific El Niños.

\section{Results}

\section{a. Observational evidence for a delayed negative feedback}

The El Niño of 1997/98 is a prominent example from the observational record of a strong Pacific warm event that was followed by boreal summer warm SST anomalies in the eastern equatorial Atlantic. A longitude versus time diagram of AVISO SSH and NCEP-NCAR wind stress anomalies along the equator (averaged over $2^{\circ} \mathrm{S}-2^{\circ} \mathrm{N}$ ), across the Atlantic basin from November 1997 to October 1998 (Fig. 4b), shows lower than normal SSH propagating eastward from January to February 1998, which is indicative of an upwelling Kelvin wave. This Kelvin wave appears to be generated by a combination of the direct response to strengthened southeasterly trades in February and a reflection of upwelling equatorial Rossby waves caused by a westerly wind stress anomaly in November/December 1997. (The westerly wind stress anomaly in late 1997 is rather unusual for an El Niño year.) In boreal summer, about 6 months after the upwelling Kelvin wave, an eastward-propagating SSH anomaly is evident with opposite sign, which is the signature of a downwelling Kelvin wave. The phase speed of the eastward-propagating positive SSH signal is $1.5 \mathrm{~m} \mathrm{~s}^{-1}$, which is close to the phase speed expected for a second baroclinic mode equatorial Kelvin wave (Schouten et al. 2005). Consistent with this wave reaching the eastern cold tongue region, a positive SST anomaly is present there in July 1998 (not shown).

The equatorial Kelvin wave that contributes to this boreal summer warming appears to be generated by the
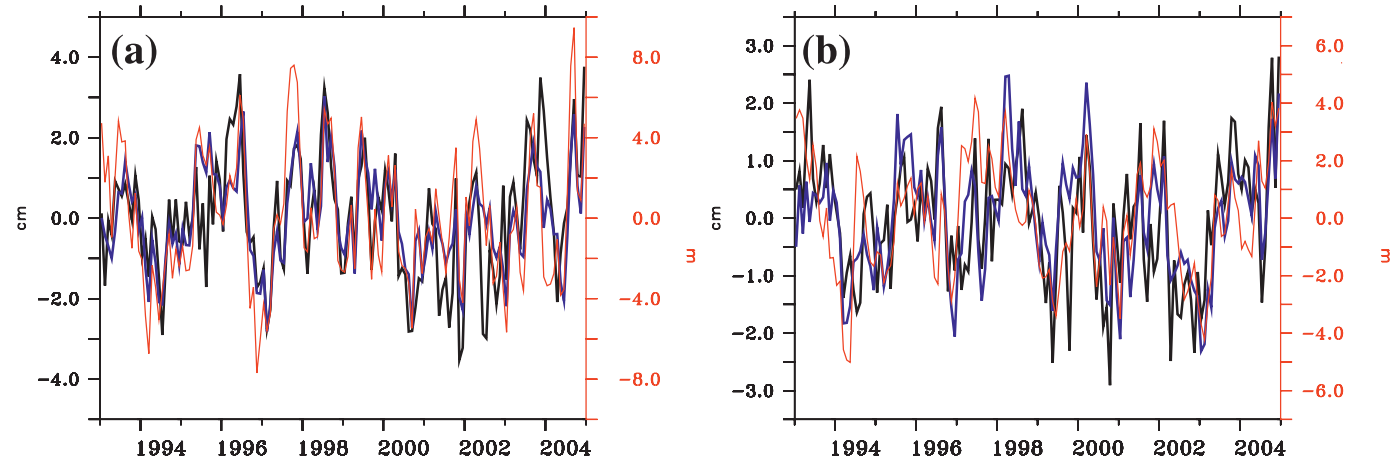

FIG. 3. Interannual SSH $(\mathrm{cm})$ and inverted $\mathrm{z} 23(\mathrm{~m})$ anomalies averaged over $40^{\circ} \mathrm{W}-10^{\circ} \mathrm{E}$ and (a) $2^{\circ} \mathrm{S}-2^{\circ} \mathrm{N},(\mathrm{b}) 2^{\circ}-5^{\circ} \mathrm{N}$ from AVISO observations (black) and NEMO-ORCA05 model (SSH blue, z23 red). 

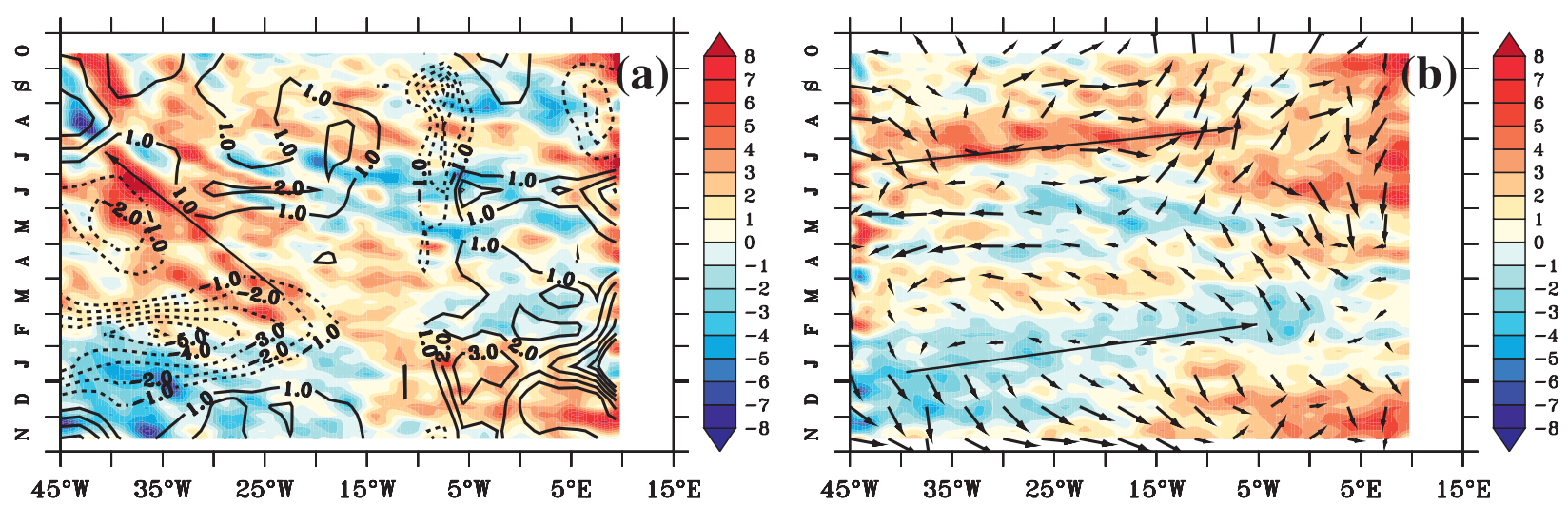

FIG. 4. Longitude vs time diagrams of weekly AVISO SSH (cm) from November 1997 to October 1998 : (a) averaged over $2^{\circ}-5^{\circ} \mathrm{N}$ with contours of NCEP-NCAR wind stress curl anomalies overlaid, and (b) averaged over $2^{\circ} \mathrm{S}-2^{\circ} \mathrm{N}$ with NCEP-NCAR wind stress anomaly vectors overlaid; long arrows indicate the wave propagation corresponding to phase speeds of (a) 0.20 and (b) $1.5 \mathrm{~m} \mathrm{~s}^{-1}$.

reflection of a downwelling Rossby wave that can be seen as a westward-propagating positive anomaly in AVISO SSH averaged over $2^{\circ}-5^{\circ} \mathrm{N}$ (Fig. 4a). The phase speed of this signal is visually estimated to be roughly $0.20 \mathrm{~m} \mathrm{~s}^{-1}$. From the linear wave model analysis by Foltz and McPhaden (2010) that allowed a direct diagnosis of the dominant wave modes, we expect wind stress forcing off the equator to excite predominantly first and second meridional mode Rossby waves of the second baroclinic mode. The second baroclinic mode appears to be dominant based on the phase speed of the reflected Kelvin wave. The phase speed of the Rossby wave is slower than expected for second baroclinic mode free wave propagation though. The likely explanation of this apparent discrepancy is that, as described in Foltz and McPhaden (2010), one does not expect to see free wave propagation in the presence of significant off-equatorial wind stress curl forcing.

The Rossby wave was generated by a negative wind stress curl anomaly in the western-central Atlantic north of the equator in February/March (Fig. 4a). The associated wind stress anomaly is likely caused by the pronounced meridional SST gradient set up by the strong 1998 boreal spring warming of the northern tropical Atlantic in response to the $1997 \mathrm{El}$ Niño event (not shown). Thus, the delayed feedback mechanism described in the introduction appears to be active in 1997/98. In the next section, data from the numerical circulation model simulation that covers more El Niño events than the observational SSH dataset are used for a composite analysis.

\section{b. Composite analysis from model data}

In this section, we analyze composites based on the model simulation described in section $2 \mathrm{~b}$. The model run spans the period 1958-2004 and includes 11 El Niño events that are defined by the model Niño-3 SST exceeding $70 \%$ of the standard deviation for at least 3 months in a row. These events occur in 1963/64, 1965/66, 1969/70, 1972/73, 1976/77, 1979/80, 1982/83, 1986/87, 1991/92, 1997/98, and 2002/03. Slight differences between observed and simulated SSTs (Fig. 2a) imply that model El Niños do not exactly coincide with, but are largely consistent with, the events defined by the NOAA National Weather Service Climate Prediction Center (http:// www.cpc.ncep.noaa.gov/products/analysis_monitoring/ ensostuff/ensoyears.shtml). Four of these $11 \mathrm{El}$ Niño events (1963/64, 1965/66, 1982/83, and 1991/92) were followed by cold eastern equatorial Atlantic SST anomalies in late boreal summer, three events (1986/87, 1997/ 98, and 2002/03) by warm eastern Atlantic SST, and four events (1969/70, 1972/73, 1976/77, and 1979/80) showed a neutral response. Warm response is defined as SST in the ATL3 region exceeding the standard deviation of the time series multiplied by 0.7 in July-September (JAS); cold response is defined as SST in the ATL3 region being less than -0.7 times the standard deviation in JAS. Using $70 \%$ of the standard deviation as a threshold has been shown to be a good measure to identify Atlantic zonal mode cold and warm events (Lübbecke et al. 2010). To differentiate between the direct and the delayed dynamical response, composites were calculated for the cold response years on the one hand (i.e., the ones that show a response consistent with Bjerknes feedbacks) and the warm and neutral response years on the other hand (i.e., the ones that show a response different from what is expected from Bjerknes feedbacks). The El Niño events of 1982/83 and 2002/03 were excluded from the analysis because they showed a behavior very different from the other composite members, as will be discussed later. The SST composites for JAS show the expected rather weak SST anomaly (Fig. 5a) for the warm/neutral response years and a pronounced cooling in the central and eastern equatorial Atlantic (Fig. 5b) for the cold response years. 

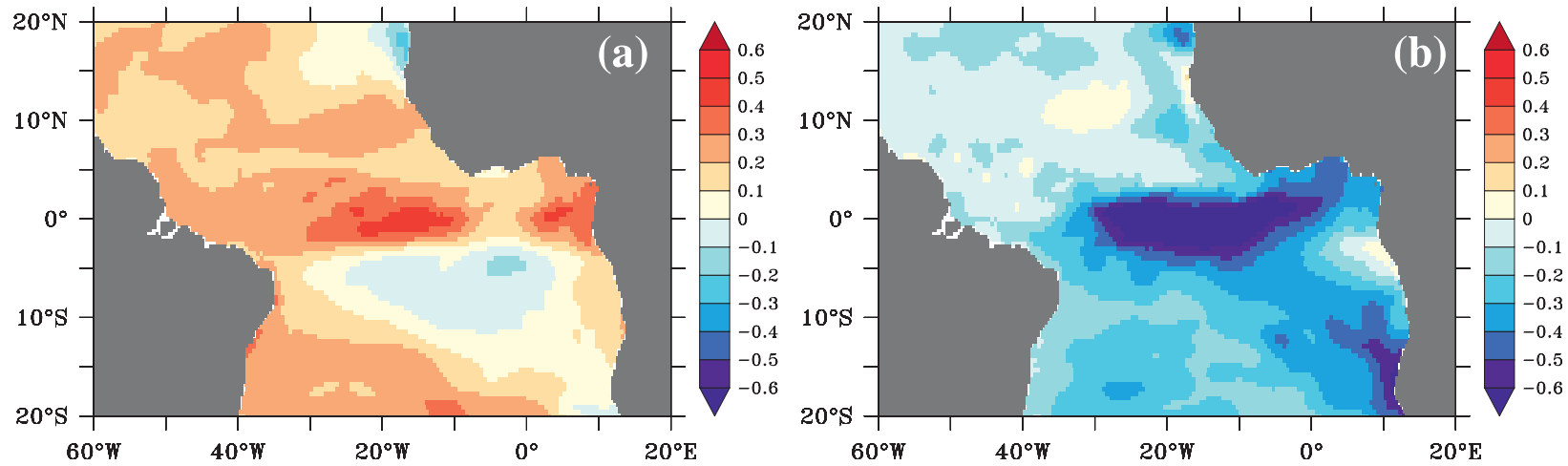

FIG. 5. Composite of tropical Atlantic boreal summer (JAS) SST anomalies $\left({ }^{\circ} \mathrm{C}\right)$ for (a) warm/neutral and (b) cold response cases from NEMO-ORCA05 model.

To understand the generation of the two different SST patterns in JAS we need to focus on the preceding months. For the warm/neutral response years, the SST composite shows a strong warming of the northern tropical Atlantic in boreal spring (Fig. 6a), while the NTA warming is rather weak in the corresponding composite for the cold response years (Fig. 6b). The strong cold anomaly off Angola that is noticeable in Fig. 6b is consistent with findings by Lübbecke et al. (2010) which state that SST anomalies in the Angola Benguela area and in the cold tongue region are closely related, with Benguela warm and cold events leading those in the EEA by one season because of differences in thermocline depths and seasonality of interannual SST variations. The relation between SST anomalies in the NTA in boreal spring and in the cold tongue region in boreal summer following an El Niño is further illustrated by a scatter diagram (Fig. 7). The linear regression curve has a slope of 0.81 (i.e., $0.81-\mathrm{K}$ ATL3 boreal summer SST anomaly per 1-K boreal spring NTA SST anomaly). The correlation between the data pairs is 0.73 , which is significant at the $95 \%$ level according to a Student's $t$ test when assuming that each pair is independent. The difference in NTA warming leads to a stronger cross-equatorial SST gradient in the warm/ neutral response years. The resulting wind stress anomaly in the eastern Atlantic to the north of the equator is associated with a strong negative wind stress curl anomaly centered around $4^{\circ} \mathrm{N}, 20^{\circ} \mathrm{W}$ in April for the warm/neutral response years (Fig. 8a). This wind stress curl anomaly is absent in the cold response composite (Fig. 8b). A negative wind stress curl anomaly can excite downwelling Rossby waves via Ekman pumping. A pronounced downwelling Rossby wave signal that emerges in March/ April at about $20^{\circ} \mathrm{W}$ and propagates westward can be seen in the thermocline depth composite for the warm/ neutral response case (Fig. 9a), which shows z23 anomalies averaged over $2^{\circ}-5^{\circ} \mathrm{N}$ across the Atlantic basin from November of the El Niño year to October of the following year. The negative wind stress curl anomaly is again clearly visible in Fig. 9a at the starting point of this wave. The inferred zonal phase speed of the Rossby wave is about $0.24 \mathrm{~m} \mathrm{~s}^{-1}$, which is (as earlier discussed for the 1997/98 observations) slower than expected for free first and second meridional mode Rossby waves of the second baroclinic mode in this range of latitudes because of the presence of the wind curl forcing. The wave reaches the western boundary in boreal summer and is reflected into a downwelling Kelvin wave that then propagates
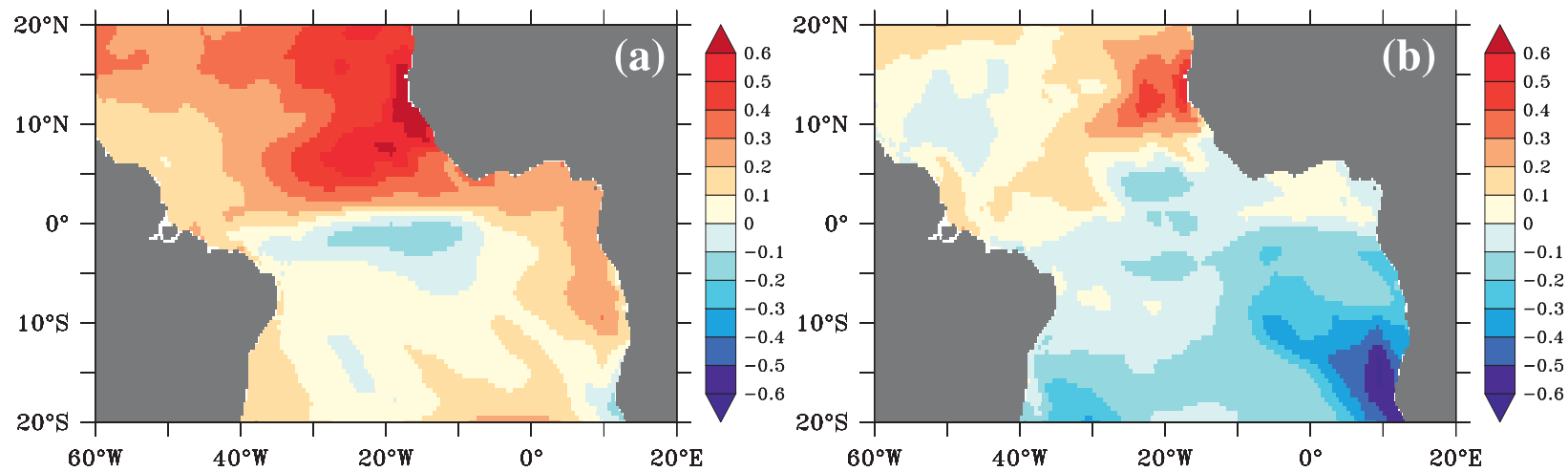

FIG. 6. Composite of tropical Atlantic boreal spring [March-May (MAM)] SST anomalies $\left({ }^{\circ} \mathrm{C}\right)$ for (a) warm/neutral and (b) cold response cases from NEMO-ORCA05 model. 


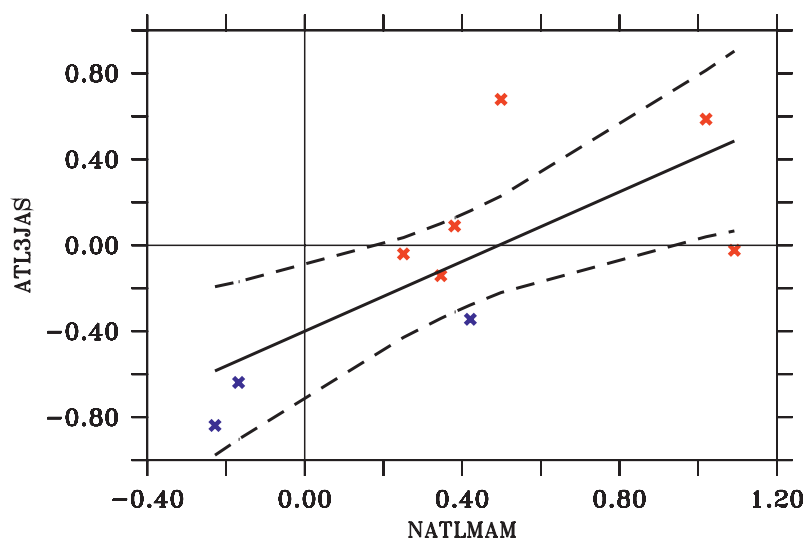

FIG. 7. Linear regression of MAM SST anomalies from the NTA $\left(5^{\circ}-15^{\circ} \mathrm{N}, 30^{\circ} \mathrm{W}-10^{\circ} \mathrm{E}\right)$ against JAS SST anomalies from the ATL3 region for warm/neutral (red crosses) and cold (blue) response years from NEMO-ORCA05 model; dashed lines indicate $95 \%$ confidence interval.

eastward along the equator and arrives in the cold tongue region around August (Fig. 9b).

There is another maximum in the equatorial thermocline depth anomaly around $35^{\circ} \mathrm{W}$ that occurs in May-June (Fig. 9b) prior to the arrival of the downwelling Rossby wave at the western boundary. This early western thermocline deepening is related to the eastwest tilt of the thermocline due to intensified easterly winds in boreal spring along the equator (as indicated by the wind vectors in Fig. 9b). This direct wind-forced response is superimposed on, and partially obscures, the Kelvin wave generated by western boundary reflection.

Second baroclinic mode equatorial Kelvin waves can cross the Atlantic basin in about 1 month, so their propagation can be illustrated more clearly using 5-dayaverage output (Fig. 10). Note that the number of composite members is reduced by one compared to the monthly output because the 5-day-average simulation is available only from 1970 onward. For the northern band, the pattern is very similar (Fig. 10a), though some additional detail is evident. For example, in the direct forcing region, the inferred phase speed is roughly $0.17 \mathrm{~m} \mathrm{~s}^{-1}$ for the 5 times daily data, speeding up to the west where the forcing is weaker to about $0.30 \mathrm{~m} \mathrm{~s}^{-1}$. For the equatorial band the 5-day-average data clearly reveal individual signals propagating to the east. The connection at the western boundary of wave processes in the off-equatorial and equatorial bands is also evident from July to August. The phase speed of the western boundary-generated Kelvin wave inferred from the eastward progression of local z23 maxima is $1.5 \mathrm{~m} \mathrm{~s}^{-1}$, which is in the range of a second baroclinic mode equatorial Kelvin wave. A downwelling Kelvin wave is associated with a depression of the thermocline and thus a subsurface temperature anomaly. When it arrives in the eastern Atlantic cold tongue area in boreal summer where the thermocline is seasonally shallow, it reduces or may even override the cooling that would otherwise have been caused by the direct dynamical response of the strengthened southeasterly trades that prevail during the first half of the composite year (Fig. 9b).

Note that the thermocline anomalies in Figs. 9 and 10 are reminiscent of the longitude versus time diagrams shown for the 1997/98 SSH observations (Fig. 4). The composite is, however, not dominated by the strong 1997/ 98 El Niño. Almost the same picture is obtained when calculating the thermocline depth anomaly excluding the $1997 / 98$ El Niño from the composite for warm or neutral response years.

For the cold response years, the weak boreal spring NTA warming seen in Fig. $6 \mathrm{~b}$ results in a different wind stress anomaly that is not associated with a strong negative wind stress curl (Fig. 8b). The wind stress curl composite in the longitude-time diagram (Fig. 11a) is rather noisy, showing both positive and negative anomalies in contrast to the well-defined negative anomaly seen for the warm/
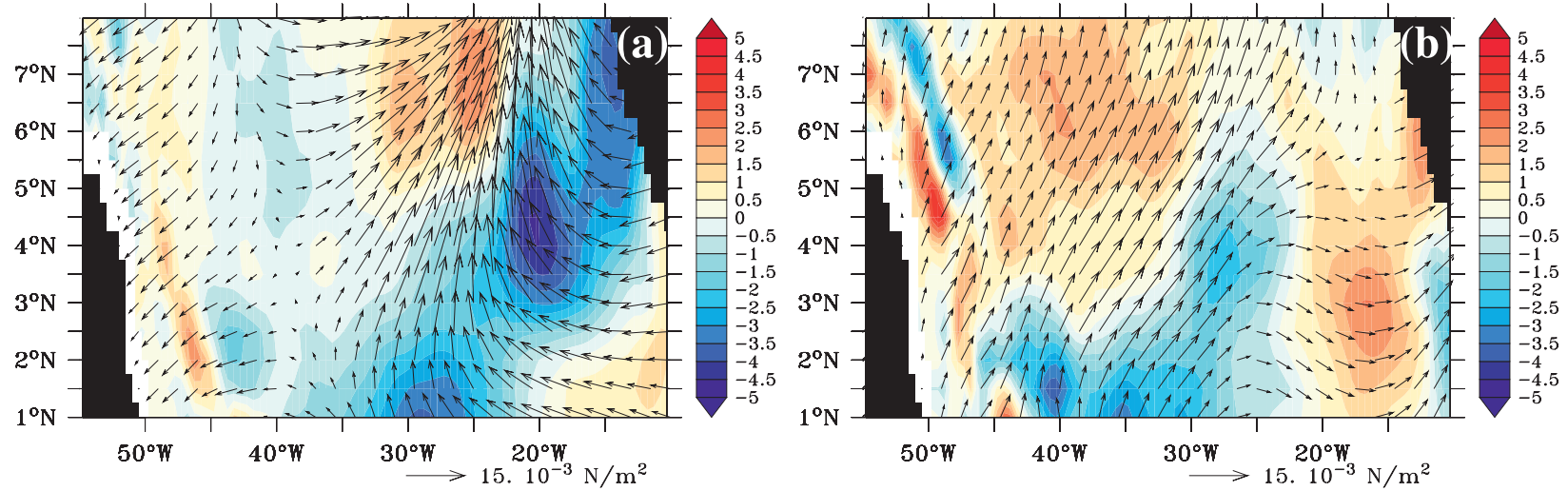

FIG. 8. Composite of April northern tropical Atlantic CORE wind stress ( $\mathrm{N} \mathrm{m}^{-2}$; vectors) and wind stress curl $\left(10^{-7} \mathrm{~N} \mathrm{~m}^{-2}\right.$; color) anomalies for (a) warm/neutral and (b) cold response cases. 

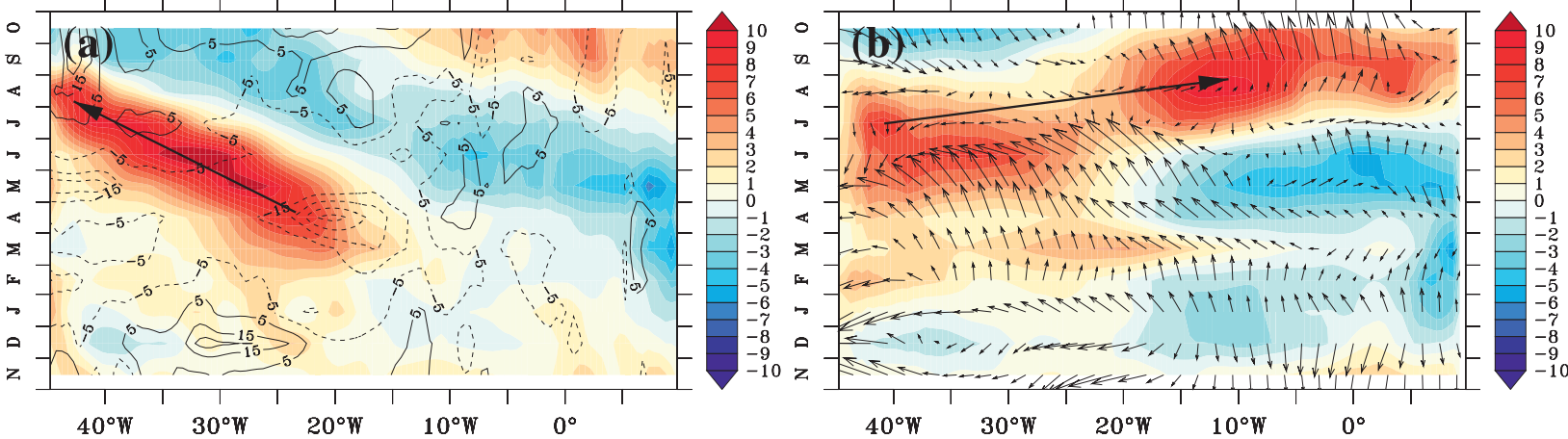

FIG. 9. Longitude vs time diagrams (monthly data) of the depth of the $23^{\circ} \mathrm{C}$ isotherm $(\mathrm{m})$ composite averaged over (a) $2^{\circ}-5^{\circ} \mathrm{N}$ with contours of CORE wind stress curl anomalies overlaid and (b) $2^{\circ} \mathrm{S}-2^{\circ} \mathrm{N}$ with CORE wind stress anomaly vectors overlaid for warm/neutral response case from NEMO-ORCA05 model; positive values denote a deepening of the thermocline, and long arrows indicate direction of wave propagation.

neutral composite (Fig. 9a). This is probably also due to the small number of years considered. Thermocline depth is shallower than normal for most of boreal spring north of the equator and in the EEA almost throughout the year (Fig. 11). There is even an indication of a weak upwelling Rossby wave propagating westward in the latitude band $2^{\circ}-5^{\circ} \mathrm{N}$. Along the equator, the thermocline is extremely shallow in the eastern part of the basin from July to October, which is consistent with the pronounced cold SST anomaly that was seen in the boreal summer cold composite (Fig. 5b). We can conclude that no delayed negative feedback acts in the cold response years. Instead the initial cooling persists and is amplified in boreal summer.

The strength of the NTA warming in boreal spring appears to play a key role in determining whether a Pacific El Niño event is followed by warm or cold EEA SST anomalies in the next boreal summer (Figs. 6 and 7). There are different reasons for the rather weak NTA warming in cold response years. In 1991/92, for example, a cold NTA can be explained by a positive phase of the
North Atlantic Oscillation (NAO; Czaja et al. 2002), while the response in 1963/64 is consistent with the hypothesis of Lee et al. (2008), who argued that the atmospheric bridge from the Pacific is not persistent enough to warm the NTA when El Niño terminates unusually early, namely, before boreal spring.

As noted above, we excluded the El Niño events of 1982/83 and 2002/03 from the composite analysis owing to their inconsistent Atlantic response. The 1982/83 El Niño was followed by a strong NTA warming and a subsequent negative wind stress curl anomaly that generated a downwelling Rossby wave. The reflected downwelling Kelvin wave, however, was impeded by strong easterly wind anomalies in the central equatorial Atlantic and thus did not reach the eastern equatorial Atlantic. Thus, 1983 was actually an Atlantic cold event year. The El Niño of 2002/03, on the other hand, was followed by a cold boreal summer NTA, which is consistent with the early termination explanation by Lee et al. 2008. Nevertheless, a weak downwelling Rossby wave and reflected downwelling
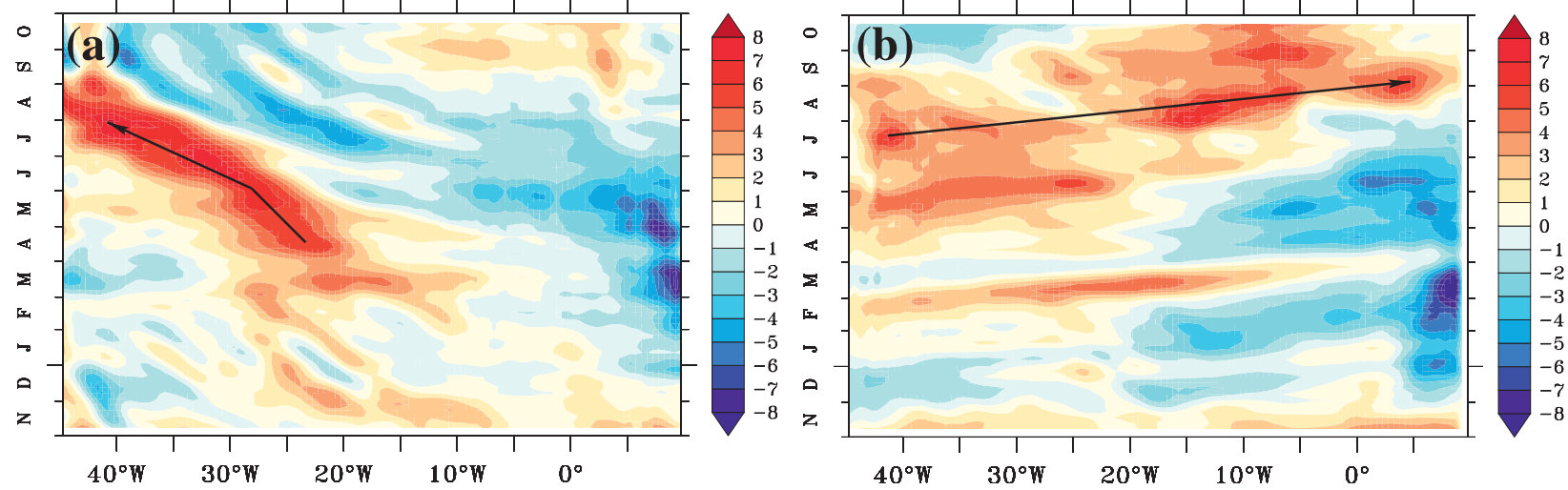

FIG. 10. Longitude vs time diagrams ( 5 times daily data, three-point boxcar filtered in longitude) of the depth of the $23^{\circ} \mathrm{C}$ isotherm $(\mathrm{m})$ composite averaged over (a) $2^{\circ}-5^{\circ} \mathrm{N}$ and (b) $2^{\circ} \mathrm{S}-2^{\circ} \mathrm{N}$ for warm/neutral response cases from NEMO-ORCA05 model; positive values denote a deepening of the thermocline, and long arrows indicate direction of wave propagation. 


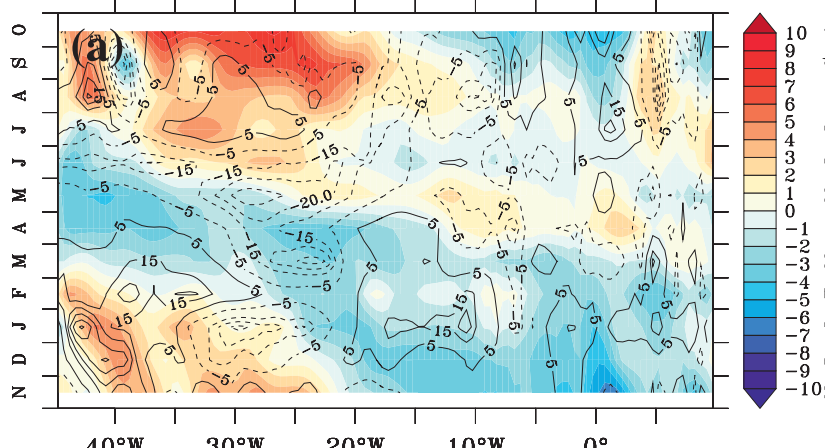

$40^{\circ} \mathrm{W}$

$30^{\circ} \mathrm{W}$

$20^{\circ} \mathrm{W}$

$10^{\circ} \mathrm{W}$

$0^{\circ}$

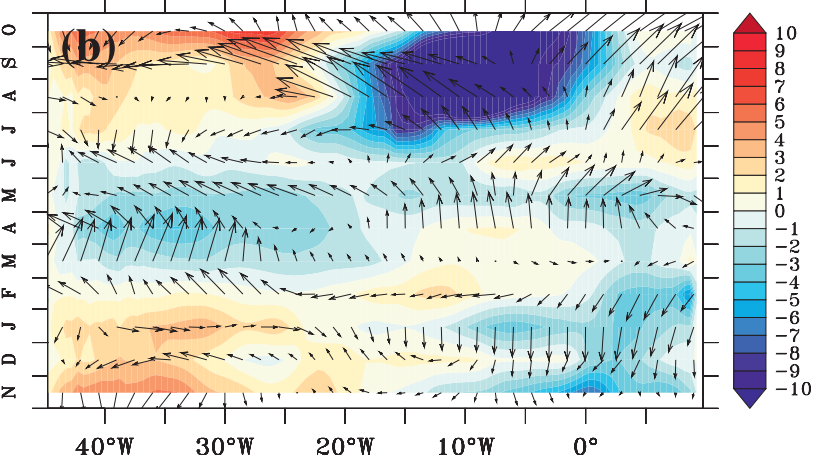

FIG. 11. Longitude vs time diagrams (monthly data) of the depth of the $23^{\circ} \mathrm{C}$ isotherm $(\mathrm{m})$ composite averaged over (a) $2^{\circ}-5^{\circ} \mathrm{N}$ with contours of CORE wind stress curl anomalies overlaid and (b) $2^{\circ} \mathrm{S}-2^{\circ} \mathrm{N}$ with CORE wind stress anomaly vectors overlaid for cold response case from NEMO-ORCA05 model; negative values denote a shoaling of the thermocline.

Kelvin wave signal appear in the SSH longitude versus time diagram and the Atlantic cold tongue SST warmed in late boreal summer 2003. These two events are good examples of the fact that interannual SST variability in the tropical Atlantic cannot be purely understood as a response to variability in the tropical Pacific and that the internal dynamics of the tropical Atlantic also need to be considered.

\section{Conclusions and discussion}

El Niño events in the Pacific strongly affect the tropical Atlantic Ocean but SST in the Atlantic cold tongue region where interannual variability peaks in boreal summer does not respond in a consistent way. Here we show that this inconsistent relationship can be explained in part in terms of a delayed negative feedback to El Niño forcing in the Atlantic.

Observational data as well as a composite analysis based on output from a global ocean circulation model were used to investigate the EEA response to El Niño. The direct dynamical response to strengthened southeasterly trades along the equator, which is a typical consequence of El Niño events, should be a cooling of the eastern equatorial Atlantic. However, in many years, a warming rather than a cooling response is observed. While part of the warming can be attributed to a general warming of the troposphere and a flux of heat from the atmosphere to the Atlantic Ocean during El Niño (Chiang and Lintner 2005), wind-forced ocean dynamics can lead to different types of response. In years with a warm or neutral response in the EEA, boreal spring warming in the NTA is found to be quite strong, setting up a strong meridional SST gradient. The subsequent wind stress and corresponding negative wind stress curl anomaly excite downwelling Rossby waves that propagate westward and reflect into downwelling equatorial Kelvin waves. When these downwelling Kelvin waves reach the EEA in late boreal summer, they counteract and sometimes overwhelm the initial cooling to kick off an Atlantic zonal mode warm event. The strong 1997/98 El Niño is an example of an event that was followed by a pronounced downwelling Rossby wave and subsequent downwelling Kelvin wave leading to warm EEA SST anomalies in boreal summer.

The strength of the NTA warming in boreal spring following the El Niño peak plays a key role in the response of the eastern equatorial Atlantic. With the exception of 1982/83, a strong NTA warming in boreal spring induces a delayed negative feedback. Conversely, this delayed negative feedback generally does not operate in cases when the NTA SST anomaly is either anomalously weak or cold in boreal spring following an El Niño. It is interesting to note that other than the effect the early El Niño termination has on the NTA warming, we can discern no obvious connection between onset, duration, strength, or type (e.g., Ashok et al. 2007) of El Niño events and their tropical Atlantic responses. This is in contrast to the results by Rodrigues et al. (2011) who found that different types of El Niño have different impacts on SST in the equatorial Atlantic.

La Niña events, like El Niño events, also have an impact on the tropical Atlantic. Thus, one might expect a delayed negative feedback to be active in the EEA response to Pacific cold events as well. However, of the 11 La Niña events in the model time series, only 4 show an Atlantic response that is consistent with the hypothesized delayed negative feedback mechanism. Most La Niñas are followed by a cold boreal spring NTA anomaly but no positive wind stress curl or upwelling Rossby waves that reflect into upwelling Kelvin waves to arrest warming in the ATL3 region. The striking difference in the tropical Atlantic response to El Niño and La Niña events - another example of asymmetry in the warm and cold phases of the ENSO cycle (e.g., Larkin and Harrison 2002; Jin et al. 2003; McPhaden and Zhang 2009)—will be the subject of a future study. 
Acknowledgments. This research was partly performed while the first author held a National Research Council Research Associateship Award at NOAA/PMEL. This work is a contribution of the DFG-supported project SFB754 (www.sfb754.de). The OGCM simulation was kindly provided by Arne Biastoch and performed at the Kiel University Computing Center. The authors thank Billy Kessler for running the modal decomposition routine. The helpful comments from an anonymous reviewer are greatly acknowledged.

\section{REFERENCES}

Ashok, K., S. K. Behera, S. A. Rao, H. Weng, and T. Yamagata, 2007: El Niño Modoki and its possible teleconnection. J. Geophys. Res., 112, C11007, doi:10.1029/2006JC003798.

Blanke, B., and P. Delecluse, 1993: Variability of the tropical Atlantic Ocean simulated by a general circulation model with two different mixed layer physics. J. Phys. Oceanogr., 23, 1363-1388.

Carton, J. A., X. Cao, B. S. Giese, and A. M. da Silva, 1996: Decadal and interannual SST variability in the tropical Atlantic Ocean. J. Phys. Oceanogr., 26, 1165-1175.

Chang, P., Y. Fang, R. Saravanan, L. Ji, and H. Seidel, 2006: The cause of the fragile relationship between the Pacific El Niño and the Atlantic Niño. Nature, 443, 324-328, doi:10.1038/nature05053.

Chiang, J. H. C., and A. H. Sobel, 2002: Tropical tropospheric temperature variations caused by ENSO and their influence on the remote tropical climate. J. Climate, 15, 2616-2631.

_- and B. R. Lintner, 2005: Mechanisms of remote tropical surface warming during El Niño. J. Climate, 18, 4130-4149.

Czaja, A., P. van der Vaart, and J. Marshall, 2002: A diagnostic study of the role of remote forcing in the tropical Atlantic. J. Climate, 15, 3280-3290.

Drakkar Group, 2007: Eddy-permitting ocean circulation hindcasts of past decades. CLIVAR Exchanges, No. 42, International CLIVAR Project Office, Southampton, United Kingdom, 8-10.

Enfield, D. B., and D. A. Mayer, 1997: Tropical Atlantic sea surface temperature variability and its relation to El Niño-Southern Oscillation. J. Geophys. Res., 102, 929-945.

Florenchie, P., J. R. E. Lutjeharms, C. J. C. Reason, S. Masson, and M. Rouault, 2003: The source of Benguela Niños in the South Atlantic Ocean. Geophys. Res. Lett., 30, 1505, doi:10.1029/ 2003 GL017172.

Foltz, G. R., and M. J. McPhaden, 2010: Interaction between the Atlantic meridional and Niño modes. Geophys. Res. Lett., 37, L18604, doi:10.1029/2010GL044001.

Griffies, S. M., and Coauthors, 2009: Coordinated Ocean-ice Reference Experiments (COREs). Ocean Modell., 26, 1-46.

Huang, B., 2004: Remotely forced variability in the tropical Atlantic Ocean. Climate Dyn., 23, 133-152.

— , P. S. Schopf, and Z. Pan, 2002: The ENSO effect on the tropical Atlantic variability: A regionally coupled model study Geophys. Res. Lett., 29, 2039, doi:10.1029/2002GL014872.

Jin, F.-F., S.-I. An, A. Timmermann, and J. Zhao, 2003: Strong El Niño events and nonlinear dynamical heating. Geophys. Res. Lett., 30, 1120, doi:10.1029/2002GL016356.

Kalnay, E., and Coauthors, 1996: The NCEP/NCAR 40-Year Reanalysis Project. Bull. Amer. Meteor. Soc., 77, 437-471.

Keenlyside, N. S., and M. Latif, 2007: Understanding equatorial Atlantic interannual variability. J. Climate, 20, 131-142.
Large, W. G., 2007: Core forcing for coupled ocean and sea-ice models. WGSF/WCRP Flux News, No. 3, Max Press, Moscow, Russia, 2-3.

, and S. G. Yeager, 2004: Diurnal to decadal global forcing for ocean and sea-ice models: The data sets and flux climatologies. NCAR Tech. Note NCAR/TN-460+STR, 105 pp.

Larkin, N. K., and D. E. Harrison, 2002: ENSO warm (El Niño) and cold (La Niã) event life cycles: Ocean surface anomaly patterns, their symmetries, asymmetries, and implications. J. Climate, 15, $1118-1140$.

Latif, M., and T. P. Barnett, 1995: Interactions of the tropical oceans. J. Climate, 8, 952-964.

— its response to ENSO. Climate Dyn., 16, 213-218, doi:10.1007/ s003820050014.

Lee, S.-K., D. B. Enfield, and C. Wang, 2008: Why do some El Niños have no impact on tropical North Atlantic SST? Geophys. Res. Lett., 35, L16705, doi:10.1029/2008GL034734.

Levitus, S., and Coauthors, 1998: Introduction. Vol. 1, World Ocean Database 1998, NOAA Atlas NESDIS 18, 346 pp.

Lohmann, K., and M. Latif, 2007: Influence of El Niño on the upperocean circulation in the tropical Atlantic Ocean. J. Climate, 20, 5012-5018

Lorbacher, K., J. Dengg, C. W. Böning, and A. Biastoch, 2010: Regional patterns of sea level change related to interannual variability and multidecadal trends in the Atlantic meridional overturning circulation. J. Climate, 23, 4243-4254.

Lübbecke, J. F., C. W. Böning, and A. Biastoch, 2008: Variability in the subtropical-tropical cells and its effect on near-surface temperature of the equatorial Pacific: A model study. Ocean Sci., 4, 73-88.

,,-- N. S. Keenlyside, and S.-P. Xie, 2010: On the connection between Benguela and equatorial Atlantic Niños and the role of the South Atlantic Anticyclone. J. Geophys. Res., 115, C09015, doi:10.1029/2009JC005964.

Madec, G., 2008: NEMO ocean engine. Note du Pôle de modélisation de l'Institut Pierre-Simon Laplace Tech. Rep. 27, 209 pp.

McPhaden, M. J., and X. Zhang, 2009: Asymmetry in zonal phase propagation of ENSO sea surface temperature anomalies. Geophys. Res. Lett., 36, L13703, doi:10.1029/2009GL038774.

_ S. E. Zebiak, and M. H. Glantz, 2006: ENSO as an integrating concept in Earth science. Science, 314, 1740-1745.

Reynolds, R. W., N. A. Rayner, T. M. Smith, D. C. Stokes, and W. Wang, 2002: An improved in situ and satellite SST analysis for climate. J. Climate, 15, 1609-1625.

Rodrigues, R. R., R. J. Haarsma, E. J. D. Campos, and T. Ambrizzi, 2011: The impacts of inter-El Niño variability on the tropical Atlantic and Northeast Brazil climate. J. Climate, 24, 34023422

Ruiz-Barradas, A., J. A. Carton, and S. Nigam, 2000: Structure of interannual-to-decadal climate variability in the tropical Atlantic sector. J. Climate, 13, 3285-3297.

Schouten, M. W., R. P. Matano, and T. P. Strub, 2005: A description of the seasonal cycle of the equatorial Atlantic from altimeter data. Deep-Sea Res. I, 52, 477-493.

Steele, M., R. Morley, and W. Ermold, 2001: PHC: A global ocean hydrography with a high-quality Arctic Ocean. J. Climate, 14, 2079-2087.

Sutton, R. T., S. P. Jewson, and D. P. Rowell, 2000: The elements of climate variability in the tropical Atlantic region. J. Climate, 13, 3261-3284.

Xie, S.-P., and J. A. Carton, 2004: Tropical Atlantic variability: Patterns, mechanisms and impacts. Earth Climate: The OceanAtmosphere Interaction, Geophys. Monogr., Vol. 147, Amer. Geophys. Union, 405 pp. 